\title{
Understanding the 'New Governance' of Food Safety: Regulatory Enrolment as a Response to Change in Public and Private Power
}

\author{
Paul Verbruggen
}

\begin{abstract}
Profound changes in the landscape of food governance fundamentally challenge the capacity of individual regulators (national, international, public and private alike) to devise legitimate and effective systems of food safety governance. As a result, we observe an increased level of coordination between public and private regulatory activities, more and more frequently transcending national (jurisdictional) boundaries. This contribution aims to develop a better understanding of how such coordination is taking place, why and at what level. It argues that the concept of 'regulatory enrolment' provides a proper analytical lens through which the nature, properties and dynamics of regulatory regimes can be better understood. Regulatory enrolment offers a strategy for coping with change in regulatory capacities and power, and increasing regime complexity. Accordingly, regulators in the domain of food safety, and perhaps others, might harness their own legitimacy and effectiveness in ensuring regulatory outcomes.
\end{abstract}

\section{Keywords}

Food safety governance, public and private regulatory activities, regulatory enrolment

\section{Introduction}

The governance of food safety has changed dramatically since the 1990s. The outbreak of recurrent major food safety crises, including Bovine Spongiform Encephalopathy (BSE), the globalisation of food supply chains and the growing concentration of economic power amongst food retailers have made fertile ground for changes in the institutions and practices of food governance. At the same time, a general perception of failing public regulation and new concerns amongst consumers about animal welfare, dietary habits, the environment and fair trade

* Assistant Professor of Global and Comparative Private Law, Tilburg Institute for Private Law, Tilburg University, the Netherlands. 
created strong demands for regulatory change. ${ }^{1}$ These changes have occurred across two key dimensions: (i) national systems of food governance have been increasingly subject to transnational influences, and (ii) public food governance has been challenged, complemented, or at times superseded, by private governance systems. Both transitions fundamentally challenge the capacity of individual regulators (national, international, public and private alike) to devise effective and legitimate systems of food safety governance. As a result, we observe an increased level of coordination between public and private regulatory activities, more and more frequently transcending national (jurisdictional) boundaries. In the literature on international relations, political economy and governance, this shift from a traditional command-and-control style of regulation towards a more coordinated, bottom-up approach has been coined 'New Governance.'

This contribution aims to develop a better understanding of how such 'New Governance' and related coordination between public and private actors is taking place within the domain of food safety, why and at what level. To that end, it builds on the concept of 'regulatory enrolment' developed by Black. Regulatory enrolment can be seen as a governance response to regulatory change and regime complexity. It presupposes that the capacity for regulatory governance is dispersed among a variety of actors, none of which holds such a central position in the regulatory arena that they can unequivocally determine outcomes. In this decentred conception of regulation, enrolment provides a normative framework for considering ways in which the capacity of the system as a whole might be enhanced effectively and legitimately by the careful deployment within it of the regulatory capacity of different actors. ${ }^{4}$

1 Terry Marsden, Robert Lee, Andrew Flynn and Samarthia Thankappan, The New Regulation and Governance of Food. Beyond the Food Crisis? (Routledge 2010) 3-23; Tetty Havinga, Donal Casey and Frans Van Waarden, 'Changing Regulatory Arrangements in Food Governance' in Tetty Havinga, Frans Van Waarden and Donal Casey (eds), The Changing Landscape of Food Governance (Edward Elgar 2015) 3-18; Paul Verbruggen and Tetty Havinga, 'Introduction to the Special Issue on the Patterns of Interplay between Public and Private Food Regulation' (2015) 6 EJRR 482, 482-84.

2 See generally, Orly Lobel, 'New Governance as Regulatory Governance' in David LeviFaur (ed), The Oxford Handbook of Governance (OUP 2012) 65; Ken Abbott and Duncan Snidal, 'Strengthening International Regulation Through Transnational New Governance: Overcoming the Orchestration Deficit' (2009) 42 Vand J Transnat'l L 501.

3 See generally, Julia Black, 'Enrolling Actors in Regulatory Systems: Examples from UK Financial Services Regulation' (2003) Pub L 63. ibid 91. 
This article argues that regulatory enrolment, and the decentred analysis of regulation it builds on, provide a proper analytical lens through which the nature, properties and dynamics of regulatory regimes can be better understood. Regulatory enrolment then offers a strategy for coping with change in regulatory capacities and power, and increasing regime complexity. To make this claim, the article will first provide in Section 2 a deeper account of the concept of regulatory enrolment and its relationship to notions of 'polycentric regulation' and 'regulatory capacity' as developed in the literature on regulatory governance. Section 3 will provide a brief, yet systematic overview of the actors currently involved in the regulatory governance of food safety, by which their relative regulatory capacity and potential for enrolment are identified. Section 4 then offers insights into how regulatory enrolment is currently taking place, between which actors, why this occurs and at what level. Next, Section 5 considers the potential for enrolment-and its proper design-as a governance response to a key change in the regulatory domain of food safety, namely the rise of global supply chains. As such, it discusses the ways in which regulatory enrolment might harness the effectiveness and legitimacy of (some) actors in ensuring regulatory outcomes. Here, the article draws on previous empirical research conducted on the interplay between various actors concerned with the regulatory governance of food safety. Section 6 concludes with the analytical and strategic importance of regulatory enrolment.

\section{Conceptualising regulatory enrolment}

\subsection{Regulatory regimes: functions, actors and space}

In the literature on regulatory governance, we find many accounts of coordination between public and private regulatory activities through enrolment of various actors in regulatory regimes. These regimes can be defined as systems of collective control attempting to influence the behaviour of businesses according to predefined standards and goals. ${ }^{5}$ These systems are considered to be organised around three elements or functions, namely a set of normative standards and goals of some kind (standard-setting), processes for detecting deviation from these standards and

5 For the definition of regulation, see generally, Philip Selznick, 'Focusing Organizational Research on Regulation' in Roger G Noll (ed), Regulatory Policy and the Social Sciences (University of California Press 1985) 363; Julia Black, 'Critical Reflection on Regulation' (2002) 27 AJLP 26. 
objectives (monitoring), and mechanisms for correcting non-compliant behaviour (enforcement). ${ }^{6}$

Regulatory regimes comprise a variety of different actors, each fulfilling different regulatory functions depending on their relative capacity. These actors might be categorised by using a very rough analytical distinction based on their institutional background, namely public (state) and private (market, non-state) actors. Regulatory regimes administered by state actors comprise standards developed through legislative processes and administrative decision-making, and that are monitored by regulatory agencies that can sanction non-compliant behaviour through legal sanctions. The archetype of a public regulator is said to be a regulatory agency in the United States ('US'), to which frequently all three regulatory functions are delegated by primary legislation. ${ }^{7}$ Consequently, a public regulator cannot only set its own standards, but also has legal powers to monitor and enforce compliance by the regulated entities (regulatees). Non-state, marketbased regimes, by contrast, are driven by private actors such as firms, associations, non-government organisations (NGOs) or combinations of these. Regimes of 'pure' or 'voluntary' self-regulation are free from active state involvement and may comprise the creation of industry codes of conduct that are monitored by peers and enforced through reputational market sanctions. ${ }^{8}$

Examples of these stylised and purely 'public' or 'private' regimes are hard to come by in practice, however. Almost inevitably, regulatory regimes will involve different kinds of actors in relation to one or more regulatory functions. For example, practices of notice and comment, public consultation and negotiated rule-making with regulatees are now common among US regulatory agencies in order to strengthen scientific and technical expertise and facilitate participation from industry and NGOs. ${ }^{9}$ Similarly, robust and effective regimes of private selfregulation are seldom void of state interference as their creation is often coerced by the threat of government action..$^{10}$ 2001) 20-35.

7 For a comparative institutional view, see generally, John Francis, The Politics of Regulation: A Comparative Perspective (Blackwell 1993). Julia Black, 'Constitutionalising Self-Regulation' (1996) 59 MLR 24; Margot Priest, 'The Privatization of Regulation: Five Models of Self-regulation' (1997) 29 Ottawa L Rev 233, 245.

9 David Weimer, 'The Puzzle of Private Rule-Making: Expertise, Flexibility and Blame Avoidance in US Regulation' (2006) 66 Publ Admin Rev 569, 570-73.

10 See generally, Guy Halfteck, 'Legislative Threats' (2008) 61 SLR 629; Adrienne Héritier and Sandra Eckert, 'New Modes of Governance in the Shadow of Hierarchy: Self-Regulation by Industry in Europe' (2008) $28 \mathrm{~J}$ Pub Policy 113. More generally, see Neil Gunningham and 
These empirical observations draw attention to the increasingly 'fragmented"11 and 'hybrid' ${ }^{12}$ character of regulation: regulation is not the product of a single regulator, but is the outcome of a process involving a multitude of regulatory actors or different sites of regulation that interact in 'complex, fluid and multidimensional ways. ${ }^{13}$ One of the most powerful accounts of this development is provided by Black. She promotes a 'decentred' analysis of regulation, which:

involves a move away from an understanding of regulation which assumes that governments have a monopoly in the exercise of power and control, that they occupy a position from which they can oversee the actions of others, and that those actions will be altered pursuant to government's demand. ${ }^{14}$

As Black explains in later writings, this analysis 'draws attention away from individual regulatory bodies, be they at the national or global level, and emphasises instead the multitude of actors which constitute a regulatory regime in a particular domain. ${ }^{, 5}$ While a decentred analysis of regulation thus denies the centrality of the state as a regulator and seeks to draw attention away from it, a polycentric approach more positively highlights the existence of multiple sites of regulation, either at sub-national, national or transnational level. At the core of both analyses is the claim that there is no 'centre' of regulation, no one position of an ultimate overseer or controller that a state or non-state actor can hold.

The understanding of regulation as decentred or polycentric invites the image of a regulatory space that is occupied by a variety of actors. The analytical construct of a regulatory space was first developed by Hancher and Moran ${ }^{16}$ based on Crouch's metaphor of 'polity space. ${ }^{17}$ The regulatory space is defined as 'the range of regulatory

Joseph Rees, 'Industry Self-regulation. An Institutional Perspective' (1997) 19 L \& Pol’y 363.

11 Colin Scott, 'Analysing Regulatory Space: Fragmented Resources and Institutional Design' (2001) Pub L 329, 334-38.

12 David Levi-Faur, 'Regulation and Regulatory Governance' in D. Levi-Faur (ed), Handbook on the Politics of Regulation (Edward Elgar 2011) 3.

13 Marie-Laure Djelic and Kerstin Sahlin-Andersson, 'Institutional Dynamics in a Re-ordering World' in Marie-Laure Djelic and Kerstin Sahlin-Andersson (eds), Transnational Governance: Institutional Dynamics of Regulation (CUP 2006) 375, 386.

14 Julia Black, 'Decentring Regulation: Understanding the Role of Regulation and Self-Regulation in a "Post-regulatory" World' (2001) 54 CLP 103, 112.

15 Julia Black, 'Constructing and Contesting Legitimacy and Accountability in Polycentric Regulatory Regimes' (2008) 2 Regul'n \& Governance 137, 139-40.

16 Leigh Hancher and Michael Moran, 'Organising Regulatory Space' in Leigh Hancher, Michael Moran (eds), Capitalism, Culture and Economic Regulation (OUP 1989) 271.

17 Colin Crouch, 'Sharing Public Space: States and Organized Interests in Western Europe' in John Hall (ed), States in History (Basil Blackwell 1986) 177. 
issues subject to public decision', including issues of safety or pricing in a particular domain. ${ }^{18}$ Because it is a space, it can be occupied and divided between different actors possessing different resources for regulation. However, understanding who occupies the space involves examining the outcomes of competitive struggles, the resources used in those struggles, and the distribution of those resources between different involved institutions. ${ }^{19}$ Of the many factors determining the shape of the regulatory space, and the relative position of the actors occupying it, Hancher and Moran draw attention to the importance of national legal culture in allowing access to the space, the element of timing and the organisational capacity of the actors. ${ }^{20}$

Again, the construct of the regulatory space emphasises that the capacity and resources for regulation are dispersed and fragmented among a wide range of actors. ${ }^{21}$ We might attempt to locate the different actors in the regulatory space by reference to two key analytical dimensions drawn in relation to these actors in the decentred and polycentric analysis of regulation, and the metaphor of regulatory space. The two dimensions are those of public-private and nationaltransnational. Accordingly, four 'quadrants' are distinguished occupying different actors possessing different capacities for regulation. ${ }^{22}$ It should be emphasised, however, that any depiction of the regulatory space is only a representation of the actors at a given time. These actors, their interests and interrelationships, are not static and are subject to change over time. ${ }^{23}$ Understanding how these interests and interrelationships evolve is now a key topic for study by scholars of regulation. Moreover, the distinction between public-private actors is problematic as one of

18 Leigh Hancher and Michael Moran (n 16) 277.

19 ibid 277.

20 ibid $279 f f$.

21 Scott (n 11).

22 See Figure 1 below. Also Abbott and Snidal provide an influential mapping of the regulatory space or landscape. Focusing on transnational standard-setting regimes, they draw a 'governance triangle', the three angles of which are formed by states, firms and NGOs. Towards the centre of the triangle, different mixes of regimes are identified, leading to a total of seven separate areas of standard-setting. In this article this conceptualisation of the regulatory space is not taken as a starting point, since, in the domain of food safety, NGOs have so far played no relevant role. Using NGOs as a separate actor would therefore have little distinguishing function. What appears more important is the variety of actors and contested interests among private market actors, that is, between retailers, ie supermarket chains, manufacturers, ie major brand-name companies, farmers, and audit service providers as certification bodies. See Ken Abbott, Duncan Snidal (n 2); See in detail Tetty Havinga, 'Conceptualizing Regulatory Arrangements: Complex Networks and Regulatory Roles' in Havinga, Casey and Van Waarden 2015 (n 1) 24-25. 
the key insights provided by a decentred analysis of regulation is that the sociopolitical distinction between public-private regulation and governance has collapsed. ${ }^{24}$ Instead, we see a rise of 'hybrid' organisations combining state and non-state actors in multiple ways. ${ }^{25}$ Also the distinction between national and transnational actors might not be so clear given the insights of contemporary studies into global governance and regulation. As observed, such regulation in fact often constitutes a multi-level affair, in which transnational standards operate in, and are subject to, domestic legal orders. It must thus interact with national rules and institutions in order to have effect. ${ }^{26}$

Therefore, what we need to study are the interactions between the various actors in the different quadrants of Figure 1. These interactions are essential for a fuller understanding of the regulatory regime. Regulatory enrolment, as will be argued below, provides a nexus through which different actors are linked in a regulatory space.

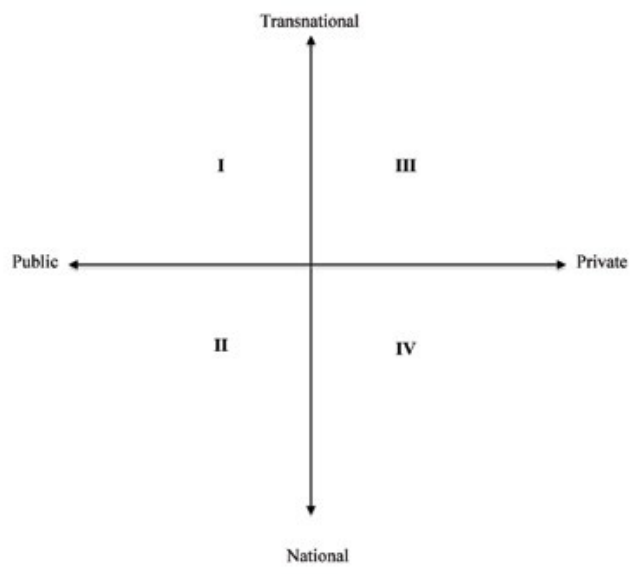

Figure 1. Regulatory space (own elaboration)

See generally, Tim Bartley, 'Transnational Governance as the Layering of Rules: Intersections of Public and Private Standards' (2011) 12 Theoretical Inq L 517; Tim Büthe and Walter Mattli, The New Global Rulers: The Privatization of Regulation in the World Economy (Princeton UP 2011); Paul Verbruggen, 'Gorillas in the Closet? Public and Private Actors in the Enforcement of Transnational Private Regulation’ (2013) 7 Regul’n \& Governance 512. 


\subsection{Regulatory capacity and regulatory enrolment}

It has been noted that a decentred analysis of regulation-including accounts of the regulatory space-has little prescriptive edge and remains descriptive for the better part. ${ }^{27}$ Proponents of this analysis simply argue for a more holistic approach to the matter of regulation, stressing the relative regulatory capacity of different actors. Normativity appears to enter the analysis only in as far as it is suggested that government should be more 'modest' in setting its regulatory objectives, for the outcomes are not a function of their regulatory activities only. ${ }^{28}$ The theory of 'smart regulation' as advanced by Gunningham and Grabosky can be seen as an early attempt to provide more normative guidance into how different actors-State, industry and civil society-and their relative regulatory capacities can and should be combined, either sequentially or simultaneously, to achieve regulatory outcomes most effectively. ${ }^{29}$ Their analysis, however, is first and foremost concerned with the deployment of enforcement capacity of actors to respond to and deter future noncompliant behaviour by the regulatees, rather than to the use of other regulatory functions such as the drafting, implementation and adoption of standards by regulatees.

A more sophisticated and systematic analysis of the way in which regulatory functions could or should be distributed between actors given the relative regulatory capacity they possess now and in the future for regulation to be effective is offered by Black. ${ }^{30}$ Building on her notion of regulation as something that is fundamentally decentred and comprises the elements of standards and goals, monitoring and enforcement, she highlights the relative capacity of the actors concerned in a regulatory regime to contribute to the purposes of those seeking to regulate (the regulators). Regulatory capacity, as she notes, refers to 'the actual or potential possession of resources plus the existence of actual and potential conditions that make it likely that those resources will be deployed both now and in the future in such a way as to further the identified goals of those seeking to regulate $(\ldots)^{, 31}$

29 Neil Gunningham and Peter Grabosky, Smart Regulation: Designing Environmental Policy (OUP 1998).

30 Julia Black (n 3).

31 ibid 72. 
Capacity thus not only refers to the possession of resources but also to the ability and willingness of the actors to put them to use. ${ }^{32}$

Six key resources for performing regulatory functions are suggested: information, expertise, wealth, authority and legitimacy, strategic position, and organisational capacity. ${ }^{33}$ Each regulatory function requires a different configuration of resources to be performed effectively. While standard-setting typically requires a high need for information, expertise and authority and legitimacy, effective enforcement appears to create greater demands for strategic positioning and authority and legitimacy. ${ }^{34}$ Clearly, the resources for fulfilling a regulatory function are not evenly distributed amongst the actors concerned with a regulatory regime. Some may have many, others few and, again, others may possess only pivotal resources for a particular regulatory function.

The actors' possession of resources is also not static. It is subject to change, much like the configuration of actors in the regulatory regime. The assessment of regulatory capacity must thus take into account the resilience of regulatory capacity and its susceptibility to changes in the underlying resources. ${ }^{35}$ Moreover, actors may possess resources directly, while they may also have indirect access to them through another actor. These properties of regulatory capacity-dispersal, change, indirect availability_invites suggestions regarding ways in which one actor possessing a different kind and degree of regulatory capacity can be functionally linked to another so as to enhance the capacity of both actors. By joining, borrowing or alternating resources, actors may strengthen the capacity of any in achieving the regulatory goals. Accordingly, the effectiveness of the regime as a whole can also be increased.

Cafaggi and Pistor offer a different approach under the header of 'regulatory capabilities' Adopting the work by Nussbaum, they embark on an assessment of the impact of regulatory regimes designed by others on individuals, collectives and entities, and their relative ability to express their preferences, choose alternative forms of regulation or determine how best to govern interdependencies between different regulatory regimes. Accordingly, their concept is much more focused on regulatees and their ability to choose to be subject to the regulatory regime, in the sense of self-determination. See generally, Fabrizio Cafaggi and Katarina Pistor, 'Regulatory Capabilities: A Normative Framework for Assessing the Distributional Effects of Regulation' (2015) 9 Regul'n \& Governance 95. Julia Black (n 3) 73ff; See generally, Colin Scott (n 11); Daniel Esty, 'Toward Optimal Environmental Governance' (1999) 74 NYU L Rev 1495. Cf Julia Black (n 3) 81. ibid 80 . 
Regulatory enrolment is essentially a strategy for linking actors possessing a different configuration of regulatory capacity in a regulatory regime so as to enhance the capacity of both. ${ }^{36}$ Identifying who the actors are and what regulatory capacity they possess is thus a key task for those actively seeking to interlink with others. Enrolment can occur consciously or unconsciously, implicitly or explicitly, and with or without changes to the formal legal structures underpinning the regulatory regime. It does not imply a level of hierarchy between the actor enrolling the other and the actor being enrolled. In fact, enrolment is frequently mutual. As Black explains, often an actor is relying on, or seeking to deploy resources of, another actor in order to achieve its own goals, while the actor being enrolled is doing the same. ${ }^{37}$

Regulatory enrolment does not, of course, guarantee regulatory outcomes, nor does it offer full control to the actor doing the enrolling over the activities of the actor being enrolled. The advantages of the strategy are to be found in the increased regulatory capacity of individual actors or the regime as a whole to achieve regulatory goals at a given moment. For example, by being able to work with more detailed information about regulatory non-compliance provided by private auditing firms, State actors may determine what type of enforcement action is required more accurately and better refine their approach to secure compliance. ${ }^{38}$ Furthermore, the ability to use or rely on additional resources may also enhance the transnational reach of public regulatory activities, which are typically confined to territorial borders. ${ }^{39}$ In Black's view, a focus on regulatory capacity and their enrolment allows for 'considering ways in which the capacity of the system as a whole might be enhanced effectively and legitimately by the careful deployment within it of the regulatory capacities of different actors. ${ }^{40}$

36 ibid 84.

37 ibid 85.

38 John Braithwaite, Regulatory Capitalism: How It Works, Ideas for Making It Work Better (Edward Elgar 2008) 96.

39 Peter Drahos, 'Intellectual Property and Pharmaceutical Markets: A Nodal Governance Approach' (2004) 77 Temple L Rev 401, 418-19.

$40 \quad$ Julia Black (n 3 ) 91. 


\subsection{Distinguishing enrolment from other theories on regulation}

The concept behind regulatory enrolment has been discussed by many others. Braithwaite and Drahos, Abbott and Snidal, and Levi-Faur speak of 'enlisting' other actors and their capacities for regulatory purposes. ${ }^{41}$ More generally, regulatory enrolment clearly links to other theories in regulation concerning the inter-connectedness of actors and (regulatory) capacity. Network theory, for example, stresses that relationships between different actors in the network-or 'webs'-are informal, complex and unstable, with no real centre of authority and power. ${ }^{42}$ However, while the linkages between different actors might thus be relatively fluid and weak, their capacity for action can be enhanced by being part of the network. ${ }^{43}$ Drahos and Braithwaite have each argued individually that a network itself may be helpful in overcoming weaknesses in regulatory capacity. They contend that the resources provided by third parties can create network effects, allowing others-either state or non-state actors-to enhance their regulatory capacity. ${ }^{44}$ As Black explains, however, regulatory enrolment 'does not necessarily imply that the actors exist in a network relationship, nor does it imply that this is an unqualified superior form of arrangement to other types of interrelationship. ${ }^{45}$

Regulatory enrolment also closely lines up with the theory of orchestration as presented by Abbott and Snidal. ${ }^{46}$ This theory provides a normative framework for states and international governmental organisations (IGOs) to use their limited capacities for regulation at transnational level to support and empower other actors-firms, NGOs, intermediaries such as certification bodies, and multi-stakeholder schemes-to deploy their capacity to regulate firms and industries. As for IGOs, orchestration occurs when 'an IGO enlists and supports and Duncan Snidal (n 2) 525; David Levi-Faur (n 12) 9. Peter Drahos (n 39) 418-19; John Braithwaite (n 38) 83-84. 
intermediary actors to address target actors in pursuit of IGO governance goals. ${ }^{47}$ Such orchestration can be 'indirect' because the orchestrator works through intermediaries to influence regulated entities ('targets'), and 'soft' because the orchestrator lacks authoritative control over intermediaries and targets. Abbott and Snidal consider orchestration to be particularly close to regulatory enrolment. As they note, 'Orchestration is a specific strategy of enrolment."

However, orchestration differs from regulatory enrolment as it departs from the assumption that state actors still hold a central position in the (transnational) regulatory space, enabling them-at least in part-to direct, steer and control social phenomena, however indirectly that may be. A purist decentred or polycentric analysis of regulation, on which Black's understanding of regulatory enrolment is cast, denies such centrality. Moreover, the theory of orchestration was developed in response to perceived gaps in the ability of state actors to respond to apparent failures to address production externalities in global markets. It is also primarily focused on, or limited to, the function of standard-setting. While regulatory enrolment is responsive to the changing role of the state in regulating global markets and its diminishing capacity for standard-setting, its application is not limited to transnational governance and standard-setting as such. It may also involve national and local-level interaction between different actors across the full range of regulatory functions in a domain.

\section{The regulatory space of food safety}

The regulatory space of food safety, including hygiene, may be dissected into spheres populated by public and private actors. In turn, each of these spheres may, again for analytical purposes only, be partitioned into a transnational and national sphere. Based on this categorisation, actors involved in the regulation of food safety may occupy a particular position within one of the four quadrants as illustrated by Figure 2 .

47 Kenneth W Abbott, Philipp Genschel, Duncan Snidal and Bernhard Zangl, 'Orchestration: Global Governance Through Intermediaries' in Kenneth W Abbott, Phillip Genschel, Duncan Snidal and Bernard Zangl (eds), International Organizations as Orchestrators (CUP 2015) 4.

48 Ken Abbott and Duncan Snidal, 'Taking Responsive Regulation Transnational: Strategies for International Organizations' (2013) 7 Regulation \& Governance 95, 98. 


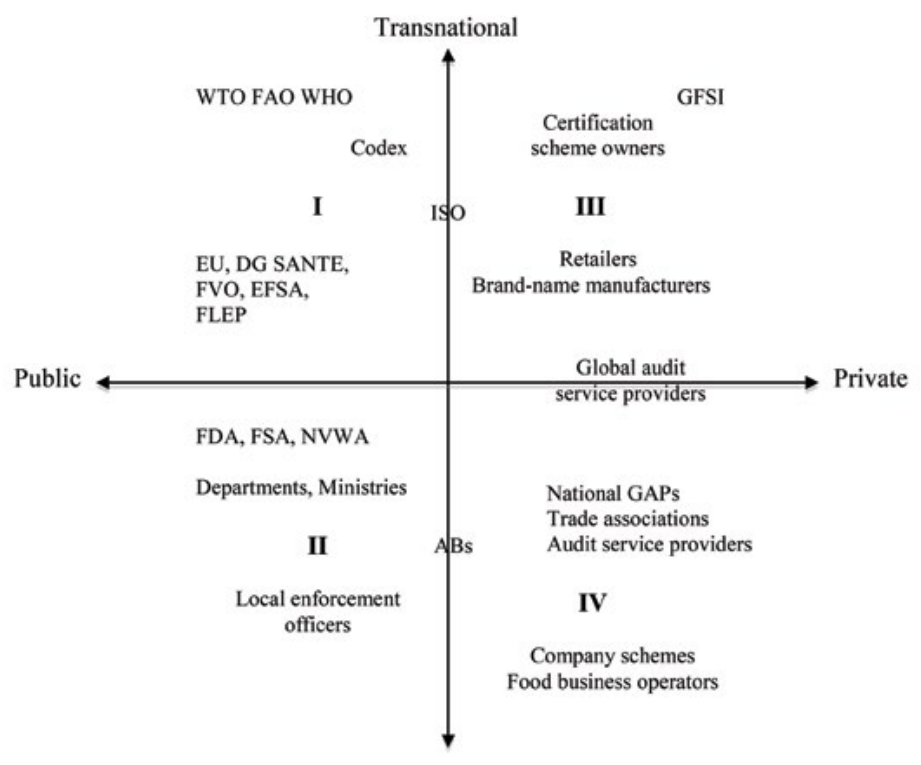

National

Figure 2 Regulatory space of food safety (own elaboration)

Abbreviations (in alphabetical order): ABs (accreditation bodies), Codex (Codex Alimentarius Commission), DG SANTE (Directorate General for Health and Food Safety-Direction Générale Sanité et Sécurité Alimentaire), EU (European Union), EFSA (European Food Safety Authority) FDA (US Food and Drug Administration), FLEP (Food Law Enforcement Practitioners), FSA (Food Standards Agency), GFSI (Global Food Safety Initiative), ISO (International Standardization Organization), NVWA (Netherlands Food and Consumer Product Safety Authority-Nederlandse Voedsel- en Warenautoriteit), WHO (World Health Organization), WTO (World Trade Organization). 


\subsection{Public sphere}

The public sphere of the regulatory space of food safety (Quadrants I and II) is populated by global, regional, national and local state actors. ${ }^{49}$ At a global level, the WTO is a key player. The international trade agreements developed by the WTO regulate global trade in food. More specifically, the Agreement on Sanitary and Phytosanitary Measures (SPS) determines the conditions under which Member States can adopt measures for the protection of the health of humans, animals and plants. One of those conditions concerns the equivalence of the measures adopted with standards developed by Codex, an expert body created by the United Nations Food and Agriculture Organization (FAO) and World Health Organization (WHO) to devise international standards and guidelines for food. Compliance by Member States with Codex standards infers compliance with the SPS Agreement. One of the key standards adopted by Codex related to food safety is the Hazard Analysis and Critical Control Points (HACCP) standard, which provides a systematic method for identifying and controlling hazards associated with food operations in the supply chain.

At a regional level, the European Union (EU) is a key institutional actor in the public sphere. The outbreak of the BSE crisis in 1996 in the United Kingdom (UK) and later in the EU can be seen as the birth of modern EU food safety law. The crisis revealed significant dysfunctions both in industry practices and the public systems supervising those practices. It also set off a process of harmonisation of national food safety laws and the creation of EU agencies in the field of food safety. ${ }^{50}$ Regulation 178/2001/EC currently provides the general legal framework for food safety regulation in the EU. ${ }^{51}$ This Regulation also created ESFA with the principal aim of providing EU Institutions and Member States with scientific and technical opinions on the adoption of EU food legislation and policies, and on the resolution of food safety incidents. To ensure effective monitoring and enforcement of the Frameworks (Hart 2015) 45.

50 Ellen Vos, 'EU Food Safety Regulation in the Aftermath of the BSE Crisis' (2000) 23 J Consum Policy 227.

51 Regulation (EC) 178/2002 of the European Parliament and of the Council of 28 January 2002 lays down the general principles and requirements of food law, establishes the European Food Safety Authority and lays down procedures in matters of food safety [2002] OJ L31/1. 
Regulation, the EU has adopted secondary legislation detailing the obligations of Member States and their authorities to control food safety. The European Commission carries out inspections in Member States through its Health and Food Audits and Analysis Directorate, formerly known as the Food and Veterinary Office. This service seeks to ensure that effective official control systems are in place and evaluate compliance with EU food safety laws within the EU. The Health and Food Audits and Analysis Directorate resides under the Directorate General for Health and Food Safety (DG SANTE) of the European Commission. This Director General also drafts and proposes EU laws on product and food safety. The Food Law Enforcement Practitioners (FLEP) provides an informal network for food law enforcement practitioners in Europe to exchange information, foster learning and cross-border co-operation, and develop mutual trust in the resolution of practical control problems. Accordingly, this network presents a subtle cross-over between the transnational (EU) and national sphere.

At a national level, food safety regulation is set and administered by ministries and departments, and national food safety agencies. These agencies take the form of independent regulatory agencies, for example, the Food and Drug Administration in the US, the Food Standards Agency in the UK, or as an executive service of a ministry, like the NVWA in the Netherlands. Food safety agencies, at least in Europe, liaise with each other either through formal institutions, such as the European Food Safety Authority (EFSA) or informal networks, such as FLEP. Enforcement of food safety laws may be the responsibility of the agencies or ministries, or they may share such responsibility with local enforcement officers at state, city or commune level.

\subsection{Private sphere ${ }^{52}$}

The private sphere of the regulatory space (Quadrants III and IV) is occupied by a range of different actors operating at transnational-global and regional-and here. As noted above (n 22), NGOs do not play a role of significance in the domain of food safety, in sharp contrast to social and sustainability aspects of the production, sourcing and marketing of food. 
national level. Certification scheme owners have become principal institutional actors in the governance of food safety. ${ }^{53}$ Schemes like British Retail Consortium (BRC), Food Safety System Certification 22000 (FSSC 22000), Global Partnership for Good Agricultural Practices (GLOBALG.A.P.), International Food Standard (IFS), Safe Quality Food (SQF) dominate agri-food supply chains and food manufacture. In a survey held among quality and safety directors of major food retailers in The Organization for Economic Cooperation and Development (OECD) countries, the respondents estimated that between 75 and 99 per cent of all food products supplied were certified on the basis of the private food standards part of the schemes. ${ }^{54}$ The schemes are governed by major retailers-for instance, Ahold/Delhaize, Carrefour, Tesco, Wal-Mart etc, multi-national brand-name manufacturers, like Kraft, Nestlé, Unilever etc, and/or global audit service providers, like Bureau Veritas, Lloyds, Société Générale de Surveillance, etc. To ensure more coordination amongst these schemes and reduce costs of multiple-and partly overlapping-audits for food business operators, scheme owners established Global Food Safety Initiative (GFSI). This organisation benchmarks individual schemes in order to provide a level playing field among these schemes, such that, once a food business is certified for one scheme, its certification is accepted under other schemes as well. ${ }^{55}$ Nonetheless, retailers and brand-name companies have been observed continuing to impose their own food safety assurance systems on actors in their global supply chains and foreign subsidiaries, mainly through strategies of Corporate Social Responsibility. ${ }^{56}$

The private standards adopted under transnational certification schemes require implementation at national, local level. Audit service providers, including auditors, certifiers, consultants, are key players in this implementation process. ${ }^{57}$

53 Spenser Henson and John Humphrey, 'The Impacts of Private Food Safety Standards on the Food Chain and on Public Standard-Setting Processes', Paper Prepared for FAO/WHO (2009), $<$ http://www.fao.org/docrep/012/i1132e/i1132e00.pdf > accessed 15 January 2016.

54 Linda Fulponi, 'Private Voluntary Standards in the Food System: The Perspective of Major Food Retailers in OECD Countries' (2006) 31 Food Policy 1, 6.

55 Paul Verbruggen and Tetty Havinga, 'The Rise of Transnational Private Meta-Regulators' (2016) 21 Tilburg L Rev 116; Fabrizio Cafaggi, 'Transnational Private Regulation: Regulating Global Private Regulators' in Sabino Cassese (ed), Research Handbook on Global Administrative Law (Edward Elgar 2016) 212.

56 Spenser Henson and John Humphrey (n 53) 4.

57 Paul Verbruggen and Tetty Havinga, 'Food Safety Meta-Controls in the Netherlands' (2015) 6 EJRR 512. 
Transnational schemes may also have national spin-offs or accept national standards as equivalent. An example is provided by GLOBALG.A.P., the most widely implemented transnational food safety standard for agri-food in the world, which has devised a benchmarking process through which it has recognised national schemes to be equivalent to GLOBALG.A.P. certification for the module against which it was successfully benchmarked. Such national standards include ChiliGAP, ChinaGAP and KenyaGAP, as well as the 'Red Tractor Farm Assurance' scheme in the UK, the Qualität und Sicherheit (Quality and Safety) scheme in Germany and the IKB Varken (IKB Pigs) scheme in the Netherlands. ${ }^{58}$ In addition there are national assurance schemes administered by national trade associations or audit service providers, such as the American Institute of Baking in the US and RiskPlaza in the Netherlands. Finally, we can distinguish individual companies in the food industry, known as food business operators, that are the ultimate targets of food safety legislation. To implement these laws, however, they may design firm-specific systems of food safety control (HACCP systems) that in turn can be enforced by national food safety agencies. ${ }^{59}$

\subsection{Hybrids}

The allocation of the actors' position in the regulatory space of food safety as set out in Figure 2 might be said to be quite arbitrary for-as we will see in detail in Section 4-actors may influence and enrol other actors positioned in different quadrants of the space. There are also a number of actors that are part of the regulatory regime of food safety that are difficult to classify as either public or private, working at national or transnational level. They are 'hybrids', either residing at the intersection of the public-private sphere, the national-transnational sphere, or even both.

Accreditation bodies (ABs) are an example of a public-private hybrid. Accreditation can be defined as an attestation that a certification body meets the requirements to carry out specific conformity assessment activities. The 
organisations providing the attestation-ABs-are key actors in the regulatory space. All the GFSI benchmarked schemes require that the certification bodies that perform the audit under the scheme have been accredited. Put simply, accredited third-party certification is now the industry standard. ${ }^{60}$ The nature of these ABs is unclear, however. In the EU, Regulation 765/2008/EC on accreditation and market surveillance lays down general principles for the operation and organisation of national ABs. ${ }^{61}$ Article 4(5) of this Regulation requires that if accreditation is not directly provided by a public authority, the Member States are held formally to recognise the accreditation activities of the national $\mathrm{AB}$ as a public authority activity. This implies that if accreditation is provided by a private law organisation, for example, a foundation or a corporation, it is attributed a semi-public law status upon formal recognition. While ABs might thus be private sector bodies, by their regulatory function, they should be considered public as far as accreditation services are concerned.

An example of a national-transnational hybrid is provided by global audit service providers. The rise of transnational private food standards has created a demand for firms that can provide audit and inspection services across the globe. Blair, Williams and Lin speak of 'a rapidly growing global army of privately trained and authorised inspectors and certifiers. ${ }^{62}$ This industry of audit service providers consists of multi-national firms such as the Bureau Veritas Group, Det Norske Veritas, Lloyds, Registro Italiano Navale, Société Générale de Surveillance, and the Technischer Überwachungsverein that have national subsidiaries or contracted auditors and inspectors on all continents. ${ }^{63}$ While these actors and their

60 Maki Hatanaka, Carmen Bain and Lawrence Busch, 'Third Party Certification in the Global Agrifood System' (2005) 30 Food Policy 354.

61 These requirements include conditions of independence, impartiality, objectivity and competency. See Articles 8 to 12 Regulation (EC) 765/2008 of the European Parliament and of the Council of 9 July 2008 setting out the requirements for accreditation and market surveillance relating to the marketing of products and repealing Regulation (EEC) No 339/93 [2008] OJ L 218/30.

62 Margaret Blair, Cynthia Williams and Li-Wen Lin, 'The New Role for Assurance Services in Global Commerce' (2008) 33 J Corp L 325, 329.

63 Société Générale de Surveillance, for example, notes to have 'over 1,800 offices and laboratories and more than 85,000 employees around the world'. See <http://www.sgs.com/en/OfficeDirectory.aspx $>$ accessed 15 January 2016. 
subsidiaries are all incorporated into national legal orders, their service provision is cross-border. ${ }^{64}$

Finally, the International Organization for Standardization (ISO) can be considered to involve a variation of hybridisation in the regulatory space of food safety. ISO develops voluntary standards that apply to a wide variety of domains, including food safety, and are available on payment of a fee. A key standard for food is the ISO 22000 standard on 'Food Safety Management Systems - Requirements for Any Organisation in the Food Chain, which was adopted in 2005 and has served as a baseline for other standards in the domain, including the GFSI's benchmarking document and FSSC 22000. Furthermore, ISO provides private standards for certification and accreditation services, including ISO/IEC 17021:2006, ISO/TS 22003, and ISO 17011:2004 which are widely used by scheme owners, ABs and even state actors to assess whether certification bodies are equipped to carry out certification services. ISO itself, however, is a private association under Swiss civil law whose membership is comprised of national standardisation bodies, which may be public, quasi-public or private in nature. ${ }^{65}$ Therefore, ISO constitutes a meta-organisation of national-public or private standardisation bodies that has, as its main objective, setting transnational standards.

\section{Strategies for enrolment}

Regulatory enrolment is a strategy that is frequently applied in the domain of food safety by different actors, for different regulatory functions, and with a view to enrolling different types of resources. We can distinguish between six different

Société Générale de Surveillance, for example, notes in a marketing communication on 'food safety, quality and sustainability solutions' the following: A Global Reach with A Local Touch: 'Our approach for delivering services to our clients is harmonised, leveraging the largest independent network of experts in the world. With a presence in nearly every single region around the globe, our experts speak the local language, understand the culture of the local market and operate globally in a consistent, reliable and cost-effective manner.' <http://www. sgs.com/ /media/Global/Documents/Brochures/SGS\%20CTS\%20Food\%20Brochure\%20 Hyb\%20EN\%202013.pdf> accessed 15 January 2016. 
avenues or strategies for such enrolment-either one-directional or mutualacross the dimensions of the regulatory space of food safety, as set out by Figure 3 .

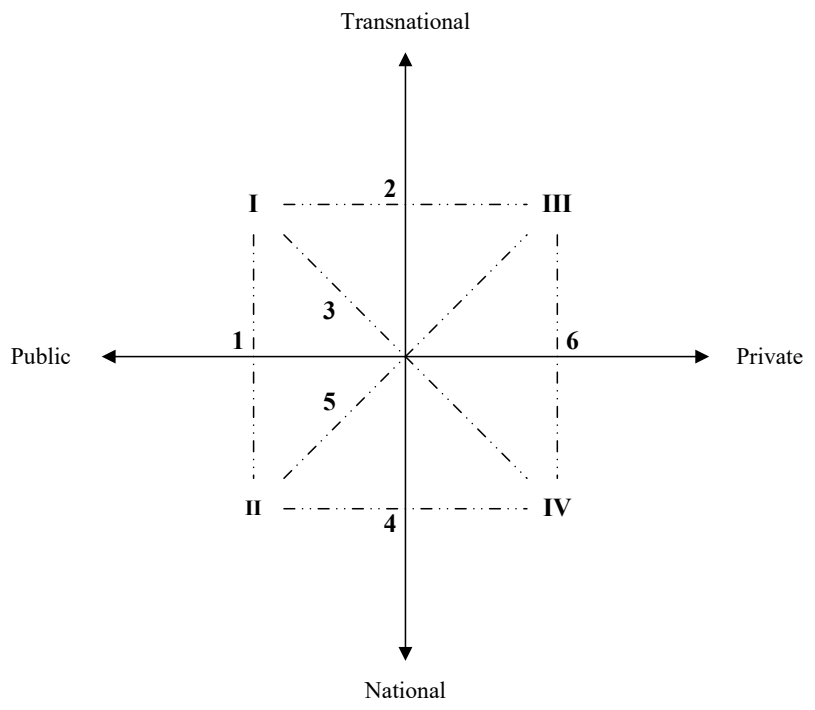

Figure 3 Regulatory enrolment in food safety (own elaboration)

The analysis below will provide examples of the avenues for enrolment, detailing the actors and resources that are enrolled, why this is taking place and how enrolment occurs, ie, consciously or unconsciously, implicitly or explicitly, and with or without changes to formal legal structures.

\subsection{Transnational public - national public}

The influence of international public law and IGOs on national food safety laws is a topic that has been well studied by scholars of food law and governance. That influence has been noted as being pervasive, in particular in the EU. As MacMaoláin observes for the UK, 'it is the EU membership which has led to the vast majority of food safety laws as they stand (...)., ${ }^{, 6}$ The same is true for other 
EU Member States. The current design of EU food safety law depends heavily on a multi-level system of governance in which the EU and its independent agency ESFA enrol national governments and food safety authorities to ensure uniform and coherent application of food safety rules across EU territory. ${ }^{67}$ Accordingly, they enrol the resources of national public actors such as information, wealth, strategic positioning and organisational capacity. As regards information, for example, the European Commission has set in place a 'Rapid Alert System for Food and Feed', which enables information to be shared efficiently between EU-28 national food safety authorities, the Commission, EFSA and other stakeholders within the European Economic Area. Accordingly, notifications of food safety risks and related outbreaks enable the EU and national authorities to devise swift, collective and efficient strategies for addressing these incidents. Conversely, national public agencies have enrolled the EU to enhance their regulatory capacity in terms of authority and legitimacy and expertise. One of the key considerations underpinning the new design of EU food safety law was the lack of trust and confidence of the general public in the capacity of national authorities to deal with cross-border food safety outbreaks in the aftermath of the BSE crisis. ${ }^{68}$ The creation of strong EU institutions and the ability to work with them would thus enhance the authority and legitimacy of national agencies. The creation of EFSA also responded to the need for national governments to have objective scientific and technical information for the resolution of food safety incidents. ${ }^{69}$ Expertise was thus sought as a resource.

\subsection{Transnational public - transnational private}

An example of the enrolment occurring between actors positioned in Quadrants II and III concerns the interplay between Codex and transnational private certification schemes as regards Codex standards. As noted, a key standard adopted by Codex is the HACCP standard, which provides a systematic method for identifying and controlling hazards associated with food operations in the supply chain. In 1969, Frank Wendler (eds), Food Safety Regulation in Europe. A Comparative Institutional Analysis (Intersentia 2006) 65.

68 Ellen Vos (n 50) 228, 242; Caoimhín MacMaoláin (n 49) 132-33.

69 Harry Kuiper, 'The Role of Scientific Experts in Risk Regulation of Foods', in Michelle Everson and Eleen Vos (eds), Uncertain Risks Regulated (Routledge-Cavendish 2009) 389. 
Codex adopted the International Code of Practice General Principle of Food Hygiene, which promoted the use of the HACCP standard. ${ }^{70}$ This Code has had a strong influence not only on the design of national food safety laws, but also on the scope and content of (transnational) private food safety regulation. Like states, private certification scheme owners have based their respective schemes on Codex's HACCP standard. Other standards adopted by Codex relating to food safety, such as standards for Good Agricultural Practice and Good Manufacturing Practice, have also been used as a basis for these schemes. ${ }^{71}$ In fact, the Food Safety System Certification 22000 scheme and Safe Quality Food Institute 2000 Code even make explicit reference to Codex as one of the authoritative sources on which their standards are based. ${ }^{72}$ Also the GFSI Guidance Document, which is used to perform the GFSI benchmarking process, is said to contain substantive elements of four different Codex standards. ${ }^{73}$

We thus observe a strong reliance by transnational private certification schemes on Codex standards in relation to the regulatory function of standardsetting. Resources that they seek to enrol to strengthen their own regulatory capacity are primarily related to authority and legitimacy, and to expertise. These schemes face an immediate legitimacy deficit because of an apparent lack of democratic process of participation or a delegation of statutory powers by national governments or IGOs. Such deficits are accentuated by the fact that traditional accountability mechanisms such as parliamentary committees, auditors, courts or ombudsman schemes do not readily apply to these private regimes. ${ }^{74}$ Being legitimate has been said to have been particularly valuable to private regulatory

70 Codex Alimentarius Commission, 'Recommended International Code of Practice General Principle of Food Hygiene' (CAC/RCP 1-1969, Rev. 4-2003).

71 Spenser Henson and John Humphrey (n 53) 37.

72 See FFSC, 'FSSC 22000 Certification, Part I - Requirements for Organizations that Require Certification' (Version 3.2, February 2015), at 3 <http://www.fssc22000.com/documents/pdf/ certification-scheme/fssc22000_part1_v3.2_2015.pdf> accessed 15 January 2016; SQFI, 'SQF Code' (Edition 7.2, July 2014) at 1, 45, 56 <http://www.sqfi.com/wp-content/uploads/SQFCode_Ed-7.2-July.pdf $>$ accessed 15 January 2016.

73 These are the International Code of Practice-General Principles of Food Hygiene (2003), Principles for Food Import and Export Inspection and Certification (1969), Guidelines for the Validation of Food Safety Control Measures (2008) and Principles for Traceability/Product Tracing as a Tool within a Food Inspection and Certification System (2006). See Kevin Swoffer, 'GFSI and the Relationship with Codex' (Presentation to CIES International Food Safety Conference, Paris 2009). See Spenser Henson and John Humphrey (n 53) 39.

74 Deirdre Curtin and Linda Senden, 'Public Accountability of Transnational Private Regulation: Chimera or Reality?’ (2011) 38 J Law \& Soc 163. 
regimes because they require that those parties affected by their authority accept these regimes and modify their behaviour in accordance with the regulatory norms or goals they set. ${ }^{75}$ WTO members have also expressed their concern that private food standards are not science-based. ${ }^{76}$ Therefore, building on well-established and widely accepted standards developed by an expert body created by United Nations organisations-FAO and $\mathrm{WHO}-$ has been a key strategy for responding to legitimacy deficits and helping to bolster the authority and capacity of the private certification schemes. ${ }^{77}$

\subsection{Transnational public - national private}

Enrolment of national private actors by a transnational public actor occurs in the case of the promotion of 'Guides to Good Hygienic Practice' by the EU and the European Commission. Regulation 852/2004/EC lays down the general hygiene requirements to be respected by food business operators in the food supply chain. ${ }^{78}$ One of the principal obligations for these operators based on Article 5(1) of this Regulation is to 'put in place, implement and maintain a permanent procedure based on [HACCP] principles'. In the literature it has been noted that the design and implementation of a HACCP system is particularly troublesome for Small and Medium-sized Enterprises (SMEs), as this approach demands great expertise and financial resources, which this type of food business operators typically lack. ${ }^{79}$ Since SMEs make up the larger part of the food industry in the EU, ${ }^{80}$ Regulation 852/2004/

WTO - Committee on Sanitary and Phytosanitary Measures, 'Summary of the Meeting of 24 October 2005, resumed on 1-2 February 2006’ G/SPS/R/39 (2006) 38.

For the strategy pursued by GLOBALG.A.P., see Donal Casey, 'The Legitimation of Non-State Regulatory Organisations: The Case of GLOBALG.A.P.s Management of Legitimacy, 19962011' (PhD thesis, University College Dublin 2014) 234-71, 281-94.

Council Regulation (EC) 852/2004 of the European Parliament and of the Council of 29 April 2004 on the hygiene of foodstuffs [2004] OJ L226/3.

'Managing Risk and Regulation in European Food Safety Governance' (2006) 23 Rev Pol'y Res 153.

Approximately 14.5 million farmers and 310,000 food and drink producing companies exist in the EU. 99\% of these food and drink companies are SMEs, which collectively represent about $42 \%$ of the revenues of the European food production market. See European Commission, 'European Industry in a Changing World. Updated Sectoral Review 2009', SEC (2009) 1111, 69-70. 
EC assists operators in ensuring compliance with the HACCP requirement in that it offers these firms the choice either to develop and implement their own companyspecific food safety management system or adopt an applicable 'Guide to Good Hygienic Practice'. At a national level, such guides are adopted and implemented by the food industry or a specific sector within it, subject to approval by a national competent government authority, such as a ministry or an independent food safety agency. The European Commission runs a registration system in which the national guides are made publicly available. In 2015, over 400 national guides were registered in this system. ${ }^{81}$ Collectively, these guides help to provide cost-efficient alternatives for food business operators to design individual company HACCP management systems. As the European Commission notes: 'Guides to good practice for hygiene and for the application of the HACCP principles developed by the food business sectors themselves should help businesses to implement HACCP-based procedures tailored to the characteristics of their production. ${ }^{, 82}$ Accordingly, these guides may assist food businesses to comply with procedural obligations expressed in the EU laws.

The inclusion of Guides to Good Hygienic Practice within the EU regulatory framework on food safety had the clear overall objective to enhance the capacity of food business operators, in particular SMEs, to comply with the newly introduced legal HACCP requirements. By enrolling national private actors involved in the adoption of these guides, the EU and European Commission sought to build on resources within the food industry to work towards implementation of the HACCP standard. An important resource these actors possess concerns information about current industry practices and demands for guidance on how to gain compliance. Trade associations indeed serve as pivotal communication channels in the supply and demand of such information as they are strategically positioned to gather input about concerns over compliance. That also makes them key actors for the adoption of common standards on HACCP compliance. As membership organisations, trade associations can be said to enjoy a strong degree of legitimacy of food business operators. Experience with the development and use of national guides provides

81 European Commission, 'Register for National Guides to Good Practice' (last updated 11 November 2015) <http://ec.europa.eu/food/food/biosafety/hygienelegislation/docs/register national_guides_en.pdf $>$ accessed 15 January 2016.

82 European Commission, 'Guidance document on the implementation of certain provisions of Regulation (EC) No 852/2004 on the hygiene of foodstuffs' (18 June 2012) at $13<$ http:// ec.europa.eu/food/food/biosafety/hygienelegislation/docs/guidance_doc_852-2004_en.pdf> accessed 15 January 2016. 
another argument for relying on private industry actors in the implementation of EU law. In the Netherlands, for example, guides on good hygiene practice have been a widely used instrument in non-industrial food sectors for over 25 years. $^{83}$ Enrolment of national guides by the EU legislature within the EU framework of food safety law also provides benefits to the private actors involved in the adoption of such guides. Approval and recognition as part of that framework also grants a greater degree of authority and legitimacy to the standard-setting activities of the private actors.

\subsection{National public - national private}

Related to the implementation of the HACCP requirements as set out by Regulation $852 / 2004 / \mathrm{EC}$ in the EU, is the interplay between national public authorities for food safety enforcement and food business operators. As Article 5(2) of this Regulation stipulates, the HACCP standard requires all food businesses along the supply chain to have in place self-assessment systems that are tailored to their business processes to identify the potential hazards concerned within their individual operations, implement and monitor controls, and document this process. This requirement does not apply to primary producers, such farmers and growers. Public food safety authorities enforce compliance with these privately established systems. This arrangement of company-level self-regulation that is approved and enforced by public actors has been discussed in the literature under the concepts of 'enforced self-regulation' and 'management-based regulation. ${ }^{, 84}$ The introduction of the HACCP standard as a regulatory requirement for food business operators in EU food safety law has been said to have triggered the widespread use of enforced self-regulation throughout the EU. ${ }^{85}$ Hygiene Regulations. Comparing the Structure of Food Controls and Regulations between Scotland and the Netherlands' (2014) 35 Recht der Werkelijkheid - Cahiers d'Anthropologie du Droit 32, 38.

84 See generally, John Braithwaite, 'Enforced Self-Regulation: A New Strategy for Corporate Crime Control' (1982) 80 Mich L Rev 1466; Cary Coglianese and David Lazer, 'Managementbased Regulation: Prescribing Private Management to Achieve Public Goals' (2003) 37 Law Soc Rev 691.

85 Marian Garcia Martinez, Andrew Fearne, Julie Caswell and Spencer Henson, 'Co-regulation as a Possible Model for Food Safety Governance: Opportunities for Public-Private Partnerships' (2007) 32 Food Policy 299. 
Enforced self-regulation is a regulatory strategy in which the regulatory resources of national public and private actors are combined and mixed to enhance the effectiveness and efficiency of regulatory outcomes. As regulatory standards are adopted by the firm itself and approved by the public agency, they are claimed to be more closely attuned to the business operations than to state regulation, more comprehensive and easier to amend. They also enjoy greater acceptance, induce fewer compliance costs for firms and thus lead to higher levels of compliance. ${ }^{86}$ In other words, by deploying the strategy of enforced self-regulation, national public agencies tap into key resources of the regulated firm to attain compliance. These resources first of all concern information about compliance. While public regulators may possess such information, and lots of it, they cannot possibly know as much as the firm itself. Also assessing and understanding the information might be more complicated for agencies than for the firm itself. In addition, the agency relies on the resources of expertise, wealth and authority of regulated firms to implement legal requirements in business processes and its staff members. Conversely, the individual firm may seek to enrol a public agency by applying for approval of its HACCP system in order to receive information about how to gain regulatory compliance. Approval also provides the firm with authority and legitimacy in pursuing its company policy vis-à-vis staff members internally, and suppliers and buyers externally.

However, the implementation of enforced self-regulation has proven to be not without its problems. While its deployment was intended to create efficiency in the allocation of scarce public enforcement resources, the regulatory strategy has been reported to be very time-consuming and laborious for individual enforcement officers, in particular when carrying out inspections at SMEs. ${ }^{87}$ The success of enforced self-regulation is fundamentally dependent on the capacity of the firms concerned to understand and manage HACCP-based systems. However, resources to do so, in particular those of expertise and funding, are typically lacking among SMEs. ${ }^{88}$ Consequently, public agencies need to allocate more time to educate food business operators on food safety hazards, which in turn leads to a situation in which the original objective of the approach-ie, efficiency-is undermined. Here, the analytical framework for regulatory enrolment as proposed by Black could provide better insight into how to overcome these problems. 


\subsection{National public - transnational private}

Enrolment of transnational private actors by national public actors is in the process of development. In the past decade, public enforcement agencies in jurisdictions such as Canada, the Netherlands, the UK and the US, have designed various collaborative regulatory arrangements with private assurance schemes to deploy their resources in more efficient and innovative ways. ${ }^{89}$ So far, these assurance schemes have been primarily national in scope. A recent development has been the coordination of public food safety controls with transnational private certification schemes. A key actor in this development is the Netherlands Food and Consumer Product Safety Authority (NVWA), which has recently developed a policy of assessing private systems of food safety controls so as to use these private systems in its own enforcement activities. Compliance under private regulatory systems would lead to a reduction in the frequency of official inspections, or sometimes, the complete absence of such inspections. ${ }^{90}$ NVWA is considering extending this policy to transnational private certification schemes benchmarked by GFSI. By doing so, it seeks to enrol the key resources these schemes possess, including information, wealth, strategic position and organisational capacity. A principal explanation by NVWA for pursuing this policy is related to the fact that its own capacity to regulate food safety has come under pressure due to the globalisation of food supply chains, and recurrent institutional reforms and budget cuts. ${ }^{91}$

GFSI, on the other hand, has been keen to engage with national and transnational public actors. Through its 'Global Regulatory Affairs Working Group' it has sought to encourage governments to understand and recognise the credibility of the GFSI process and to gain recognition by public regulators in Canada, the EU and US of GFSI-benchmarked schemes as an accepted tool to help them prioritise their food safety compliance resources and factory inspection. ${ }^{92}$ By pursuing this strategy of engagement, GFSI seeks to enrol the authority and legitimacy of public actors, while sharing information on how they might design countries, see Marian Garcia Martinez, Andrew Fearne, Julie Caswell and Spencer Henson (n 85); Paul Verbruggen and Tetty Havinga (n 57). ibid 514 .

92 Tetty Havinga and Paul Verbruggen, 'The Global Food Safety Initiative and State Actors: Paving the Way for Hybrid Food Safety Governance' in Paul Verbruggen and Tetty Havinga (eds), Hybridization of Food Governance: Types, Trends and Results (Edward Elgar, forthcoming). 
accreditation programmes for enrolling GFSI-benchmarked schemes in inspection and enforcement policies. It has been widely acknowledged that third-party certification schemes benchmarked by GFSI face problems in terms of auditor competence and auditor independence. ${ }^{93}$ Enrolling national governments and IGOs in its regime is part of a wider effort to address these issues. ${ }^{94}$

\subsection{Transnational private - national private}

Finally, transnational and national private actors may enrol each other's resources to strengthen their capacity to achieve their respective regulatory goals. An example is provided by GLOBALG.A.P., which, as noted above, provides for a benchmarking process through which national schemes are recognised to be equivalent to GLOBALG.A.P. certification for the module against which they have been successfully benchmarked. As a result, farmers certified by the benchmarked national schemes benefit from the worldwide application and acceptance by GLOBALG.A.P. of certification in markets for primary produce, including fruit and vegetables, dairy, beef, poultry, pigs and plants. This is a dominant motivation for national schemes to apply for the benchmarking process. As some observers have noted, GLOBALG.A.P. benchmarking is 'a marketing instrument to expand export market. ${ }^{95}$ After all, if national schemes succeed in being benchmarked, they can offer their (potentially) certified farmers the prospect of being able to access global supply chains for primary produce and enter the most profitable markets (EU, North America, Australia), which are typically dominated by major Western supermarket chains. ${ }^{96}$ The key resources these national schemes thus enrol concern the strategic positioning, organisational capacity, and authority and legitimacy of GLOBALG.A.P. as the world's biggest certification scheme for primary produce. For GLOBALG.A.P., on the other hand, the incentive to organise enrolment through its benchmarking process is to be able to coordinate its own regulatory activities with

93 Timothy Lytton and Lesley McAllister, 'Oversight in Private Food Safety Auditing: Addressing Auditor Conflict of Interest' (2014) Wis Law Rev 289, 297-304.

94 Tetty Havinga and Paul Verbruggen (n 92).

95 Olga Van der Valk and Joop van der Roest, 'National Benchmarking against GlobalG.A.P.: Case Studies of Good Agricultural Practices in Kenya, Malaysia, Mexico and Chile' Report 2008-079 (April 2009) <http://edepot.wur.nl/11453> accessed 15 January 2016.

96 Paul Verbruggen, Enforcing Transnational Private Regulation: A Comparative Analysis of Advertising and Food Safety (Edward Elgar 2014) 181-82. 
different and, at times, competing national private food safety regimes. Moreover, it enrols resources such as information, expertise and strategic position from local actors to be included in the GLOBALG.A.P. standard-setting procedures headed by its national technical working groups. Also such enrolment has been considered a key strategy of GLOBALG.A.P. in managing its legitimacy vis-à-vis state and nonstate actors. $^{97}$

\section{Regulatory enrolment as a governance response to change}

A key contention of the detailed analysis of the regulatory capacity and related resources of different actors constituting a regulatory regime, and in turn the potential for mutual regulatory enrolment is that it provides 'a normative framework for considering ways in which the capacity of the system as a whole might be enhanced effectively and legitimately by the careful deployment within it of the regulatory capacity of different actors. ${ }^{98}$ Such an analysis also provides a lens through which governance response to regulatory change can be designed. As noted, both the configuration of actors and their relative resources are subject to change. ${ }^{99}$ Changes may thus require the search for enrolment of other and new actors, or other and newly acquired resources.

The domain of food safety has been subject to tremendous changes in the last two decades that have affected both positively and negatively the regulatory capacity-or power if you will-of actors in that domain. ${ }^{100}$ One transformation stands out, however, and that is the rise of global supply chains. In the following subsection, this change is discussed in greater detail, as well as the potential for the strategy of regulatory enrolment as a response to it.

\subsection{Global chains and national enforcement agencies}

The food industry consists of firms that are concerned with the farming and production, packaging and distribution, and retailing and catering of food and

100 Terry Marsden, Robert Lee, Andrew Flynn and Samarthia Thankappan (n 1) 3-23; Tetty Havinga, Donal Casey and Frans Van Waarden (n 1) 3-18. 
beverages. Food supply chains link the operations of these firms and include, at one end, a strongly fragmented market for producers, including farmers, growers and, at the other end, a very concentrated market dominated by major retailers, ie, supermarket chains. In the US, the top five supermarket chains accounted for almost $40 \%$ of retail food turnover in 2000, while in 1993 they accounted for some $25 \% .{ }^{101}$ In most European countries the five largest retailers account for between $50 \%$ to over $70 \%$ of retail food. ${ }^{102}$ In addition, retailers in Western capitalist economies have been increasingly sourcing food products and ingredients across geopolitical boundaries, thus increasing the distance over which food is shipped and the number of jurisdictions they cross. ${ }^{103}$ These trends combined have created an environment in which 'global food retailing increasingly resembles an international oligopoly composed of a limited number of multinationals with minor brand producers and non-branded producers being obliged to comply with the requirements and conditions set by retailers. ${ }^{104}$

For a single public enforcement agency, the global scope of supply chains poses major challenges for its regulatory capacity to ensure safe food. While these chains have become increasingly global and frequently involve stages of production in different foreign territories, its own jurisdiction remains territorially defined. Furthermore, the sheer volume of trade in food products makes compliance with food safety regulation more troublesome and costly. In the Netherlands, for example, this is considered a serious problem since the country plays a significant role in the global trade of food. It leads global trade in vegetables - ranked highest with some $12 \%$ of global trade-while for other food products its share is significant too. ${ }^{105} \mathrm{To}$ retain this position, the Netherlands has a strong interest in ensuring the safety of imported food, yet this task might simply be impossible for a single public agency to meet adequately.

The loss of strategic positioning by national food safety agencies in a global context and a lack of authority and legitimacy to regulate food production in other

101 Lawrence Busch and Carmen Bain, 'New! Improved? The Transformation of the Global Agrifood System' (2004) 69 Rural Sociol 321, 330.

102 OECD, 'Private standards and the shaping of the agro-food system', Doc. No. AGR/CA/ $\operatorname{APM}(2006) 9 / F I N A L$ (Paris 2004) 11-12.

103 Linda Fulponi (n 54), 6-7.

104 Codex Alimentarius Commission (n 65) 5.

105 UN International Merchandise Trade Statistics 2011, 'Vegetables, fresh, chilled, frozen, simply preserved; roots $054^{\prime}<$ http://comtrade.un.org/pb/FileFetch.aspx?doc $\mathrm{ID}=4527 \&$ type $=$ commoditypagesnew $>$ accessed 15 January 2016 . 
countries invites these agencies to think about ways in which they could strengthen their regulatory capacity by enrolling the resources of others. In this context, transnational private certification schemes have entered the scene. ${ }^{106}$ Prominent agencies such as the FDA in the US, the Canadian Food Inspection Agency and NVWA in the Netherlands are engaging with GSFI and its individual benchmarked schemes to pave the way for the integration of these schemes in official inspection and enforcement policies. ${ }^{107}$ State actors thus seek to enrol critical resources of information, wealth, strategic position and organisational capacity in ever more globalising supply chains.

However, the enrolment of these transnational private certification schemes by national food safety agencies raises important questions about the design of such enrolment and the consequences in terms of democratic accountability of the agency doing the enrolling. For one thing, compliance with these schemes does not provide an absolute warranty for regulatory compliance under the legal framework. Public concern has increased following incidents of false and fraudulent certification within the food industry. A study carried out by the Dutch NVWA indicates that violations of food safety laws are still regularly observed amongst the firms that are certified for GFSI-recognised schemes, including the BRC Global Standard, IFS and FSSC $22000 .^{108}$ Furthermore, auditors working under these schemes are paid by the audited food business operators, a situation which constitutes a structural conflict of interest between the financial interests of the auditor and protecting the public from food safety incidents that needs addressing. ${ }^{109}$ Also the fact that the functions of third party audits do not overlap with those of official inspections and that certain methodologies, such as sample testing, are not used limits the use of private schemes by public actors.

Public actors are thus challenged to create operational frameworks within which they can assess and control how and under what conditions they integrate GFSI-benchmarked certification schemes into their policies for official inspection and enforcement. One key condition appears to be adequate information-sharing arrangements so that relevant changes in the status of certified firms are instantly

Errol Meidinger, 'Private Import Safety Regulation', in Cary Coglianese, Adam M. Finkel and David Zaring (eds), Import Safety: Regulatory Governance in the Global Economy (University of Pennsylvania Press 2009) 233.

107 Havinga and Verbruggen (n 92).

108 Hans Beuger, 'Overheidstoezicht en certificatie: Verhogen betrouwbaarheid vergt inspanning van alle betrokkenen' (2012) VMT 20, 21.

109 Timothy Lytton and Lesley McAllister (n 93) 304. 
communicated between the agency and a certification scheme. ${ }^{110}$ Reliable data on the status of individual certified firms and periodic meta-data on changes made to the substantive standards of the schemes, licenses and accreditations of certification bodies performing compliance audits are fundamental to ensuring trust between the agency and the scheme, and indeed to the effectiveness of the enrolment strategy. It has been observed that legal obstacles, eg, the professional confidentiality obligations of private auditors incorporated into the service contracts signed with food business operators, constitute institutional obstacles to ensuring the proper exchange of information between private schemes as regards non-compliance. ${ }^{111}$ This example also points to the limits of regulatory enrolment. As noted, the strategy does not offer full control to the actor doing the enrolling over the actor being enrolled.

\section{Conclusion}

Regulatory enrolment can be seen as an important contemporary governance response to changes in regulatory power. The study of, and engagement with, different actors occupying the regulatory space possessing a different configuration of resources for regulation allows actors to build their own regulatory capacity in new, uncertain and complex circumstances. The domain of food safety provides a wealth of information and examples of how, why and at what level actors enroll others for the purpose of achieving their regulatory goals. The principal strength of the concept of regulatory enrolment as developed by Black lies in the detailed analytical assessment it proposes of the actors, their relative capacity and underlying resources for regulation, as well as their deployment of such resources for specific regulatory functions. 'New Governance' is thus broken down into manageable units of analysis, without losing sight of the interplay between actors and their capacity to engage in regulatory activities. The disentangling of the properties of actors and the dynamics between them in a regulatory regime offers a proper analytical lens through which the nature of a regulation regime can be better understood and the capacity of that regime as a whole can be enhanced in smart and innovative ways.

$110 \quad$ Paul Verbruggen (n 96) 251.

111 Verbruggen and Havinga (n 57) 522. 